\title{
O direito na Península Ibérica
}

\author{
Lino de Morais Leme \\ Cateărático de Direito Civil na Faculdade \\ de Direito da Universidade de São Pauıo.
}

\section{Invasão dos fenícios e dos cartagineses}

Os primeiros habitantes da península ibérica, como do resto da Europa, foram provavelmente povos de origem asiática, aos quais se agregaram outros vindos da África. $\mathrm{E}$ aí se encontraram turdetanos, célticos, iberos, túrdulos, vetones ou vectones, egípcios, fenícios, gregos, etc. ,

Os fenícios invadiram a península no sec. 15 a.C., aí fundaram cidades, (1) introduziram seus costumes, religião, leis e sistema político. Não haviam êles consolidado o seu domínio nove séculos depois, quando chegaram os cartagineses, que, sob o comando de Amilcar, Asdrubal e Anibal, se instalam na península, certamente bem acolhidos pelo povo da mesma nação, que aí encontraram.

Naturalmente, se se remontar aos primeiros tempos, não se pode dizer, dos habitantes da península, que êles "magis ferarum quam hominum esse", (2) e, como dizem os historiadores romanos, "vitam piscium vivebant, ubi major devorat minorem" (3).

Mas, após séculos, era natural que entre êles se fortalecesse o culto da religião, com o amor da família e a observância de princípios morais e jurídicos. É assim que guardavam a fé dos juramentos; os notaveis se abstinham de vinho; as mulheres podiam escolher seus maridos, e cultua-

(1) Cadiz, Málaga, Sevilha, Córdova e outras.

(2) MeLiI Freirir, Hist. juris civilis Lusitaniae.

(3) Thucyd, Strab., Pauson, Ovid., apud MeLliI FreirII. 
vam a castidade por tal forma, que o adultério nem pelo nome era conhecido.

\section{A cunquista romana}

No ano 205 a.C., depois que Aníbal foi para a Itália, Cipião, o Africano, implanta o domínio romano na península que, em 38 a.C., foi solenemente incorporada ao império romano.

É um período de grande prosperidade para a península, que é dividida em duas, Citerior e Ulterior, separadas pelo rio Ebro. Augusto a dividiu em tres províncias - Bética, Tarragonense e Lusitana.

No tempo de César, Lisboa recebe o titulo de Municipium Civium Romanorum, do que resultava, para os seus habitantes, o jus civitatis.A êsse tempo os vencidos se governavam por suas leis, e os vencedores pelas leis romanas.

Adriano, originário da península, ascende ao trono, e, conhecendo o inconveniente, para os cidadãos, da diversidade de leis e de direitos, publicou um Édito, no qual definiu princípios jurídicos imutaveis e perpétuos, tanto para Roma,- como para as províncias. Depois o imperador Antonino Bassiano concedeu direitos iguais a todos os súditos do Império Romano, pelo que passaram os vencidos a se reger pelas leis romanas.

\section{O domínio dos visigodos}

No século $5 .^{\circ}$ da era cristã, a península é invadida por bárbaros - os vândalos, os suévos, os álanos, expulsos pelos visigodos, que consolidaram o seu dominio, sendo Imperador Leovigildo, com quem começa o império visisótico, que vai de 584 a 711 , sendo Rodrigo o último rei. 
Sob o domínio dêles havia uma lei para os vencedores - a Lex romana visigothorum - Corpus legum, ou Breviarium Alariciani ou Aniani, e, para os vencidos, as suas leis peculiares, ou seus usos e costumes $\left({ }^{2}\right)$. Recesvindo, porém, no fastígio do império visigótico (em 650), proscreveu o uso do direito romano, e, assim, começaram todos a usar o mesmo Código - o Forum judicum, traduzido para o espanhol, sob o título de Fuero Juzgo, adotado, em 693, com o nome de Codex legum, ou Lex visigothorum, quasi todo copiado do direito romano em vigor na península, exceto em matéria de direito criminal, em relação ao qual admitiam os tormentos, o suplício de água quente, a flagelação, a morte. Não podia a filha casar-se contra a vontade do pai, e não havia matrimônio sem dote. $O$ julgamento começava pela citação. A prova era feita por escrituras e testemunhas idôneas, sendo subsidiário o juramento. Qualquer pessôa podia defender, em Juízo, o direito seu, ou o alheio; a mulher, porém, sòmente podia defender o seu direito. Providências eram tomadas para colocar as partes em igualdade, na lide, e para evitar que o poderoso usasse de seu poder.

\section{o domínio árabe}

Vencido Rodrigo pelos sarracenos, que, em multidão imensa, penetram na península, ficou esta sob o jugo dos árabes. Se os arabes exerceram poderosa influência civilizadora - do que deixaram, na língua, numerosos traços, e do que é testemunha o califado de Córdova, que foi um poderoso facho de luz -, contudo êles se contentavam com o império e com o poder de vida e de morte, deixando em vigor o direito e as instituições que encontraram; pelas leis

(1) Nome com que foi promvilgado em 693.

(2) Tanta nimirum erat Gothorum principum humanitas, ut gentibus devictis suas leges servarent, et optiones darent, qua lege uti vellent (M. Freire, o. c., p. 23). 
árabes eram decididas as controvérsias entre êles, ou entre um árabe e um cristão. Também em matéria religiosa era grande a tolerância dos dominadores, ao contrário do que sucedia com os visigodos.

Os cristãos, refugiados nos montes das Astúrias, aclamam rei a Pelágio, de sangue real gôdo, que, tendo exíguo poder, no começo, viu o mesmo crescer e ampliar-se, ficando sob sua autoridade a Galiza, Castela e a Lusitânia. Dessa linhagem é Afonso VI, cujo neto, Afonso Henriques, funda a monarquia portuguêsa, em 1139.

\section{Os forais}

Durante a dominação árabe, desenvolvem-se os forais, que perduraram, em Portugal, até 1832, e que o Código Civil espanhol, que é de 1888, ainda reconhece, verbis: "En lo demás, las provincias y territorios, en que subsiste derecho foral, le conservarán por ahora em toda su integridad, sin que sufra alteración su actual regimen juridico, escrito o consuetudinário, por la publicación de este Código, que regirá tan solo como derecho supletorio en defecto del que lo sea en cada una de aquellas por sus leyes especiales" $\left.{ }^{1}\right)$. Os forais assumiram diferentes finalidades: foram a princípio cartas pelas quais eram concedidas ferras para povoamento, tendo os contemplados direitos mais ou menos extensos e obrigando-se a certos tributos ou serviços; outros eram verdadeiras leis civis ou criminais, econômicas e administrativas, concedidas a um conselho existente ou que se constituira, em que faltavam costumes ou leis consuetudinárias, ou em que elas devessem ser reformadas; e outros, em que eram constituídas enfiteuses genéricas. Êles foram como que a carta de alforria do município, defendendo os burgueses contra a tirania da nobreza, e tornando-se, dest'arte, um verdadeiro direito municipal. À medida que eram libertados do domínio árabe, as cidades foram recebendo os seus forais, que lhes me-

(1) Art. 12. 
lhoraram as condições sociais, econômicas e administrativas. Entre êles deve citar-se o Fuero viejo, de Castela, em princípios do séc. $13 .^{\circ}$, que é um notavel monumento histórico.

\section{A legislação de Castela}

De Afonso $X$, o Sábio, filho de D. Fernando, até o advento dos Reis Católicos, aparecem em Castela, ao lado de Fueros e Ordenamientos, a Lei das Sete Partidas, (1) mandada fazer por Afonso X, terminada em 1265 e dividida em sete partes (daí o seu nome), como o Digesto e os Decretales.

\section{O direito sob D. Diniz}

Essa lei foi traduzida em Portugal, ao tempo de D. Diniz (1279-1325), durante cujo reinado tão notaveis reformas foram feitas, especialmente no direito, que perduraram por séculos afóra $\left({ }^{2}\right)$. Notemos apenas que ela suprimiu o juramento, em matéria contratual, que regulou as obrigações e contratos das pessôas encarceradas, bem assim a obrigação daquele que se recusa a fazer o contrato prometido, o direito de sucessão do filho natural à herança do pai plebeu, dispôs sôbre a desherdação do filho

(1) A 1.a Partida tem 24 títulos, trata do direito natural, das leis, do uso e do costume, e do direito canônico e eclesiástico. A $2{ }^{a}$ tem 31 títulos e se refere à organização política. A 3.a, com 32 títulos, trata da organização judiciária e do direito processual. A 4. ${ }^{\mathrm{a}}$ tem 27 títulos e 256 leis; trata dos esponsais, do casamento, dos bens dotais e parafernais, do pátrio poder e da filiação. A $5 .^{a}$ dispõe sobre obrigações e contratos, tem 15 títulos e 274 leis. A 6. ${ }^{\mathrm{a}}$, com 19 títulos e 272 leis, abrange o direito sucessório. A 7. ${ }^{\mathrm{a}}$, com 34 títulos e 363 leis, é o Código Criminal.

(1) Melo Freire, págs. 44-52. Foi ele quem restabeleceu o uso da lingua latina nas leis, no fôro e nas próprias escrituras particulares. 
que se casa sem o consentimento do pai, taxou os salários dos tabeliães e escrivães, proibiu os direitos de sucessão em favor das Igrejas e dos mosteiros, e que essas instituições adquirissem bens imóveis. Foi êle igualmente quem decretou a fundação da Universidade de Lisbôa, transferida para Coimbra em 1308.

\section{As Ordenações Afonsinas e as Manuelinas}

D. João I, Mestre de Aviz, filho bastardo de D. Pedro I, é aclamado rei nos comícios de Coimbra $\left({ }^{1}\right)$. O rei morrera sem filho e cognatos que lhe pudessem suceder, e a filha Beatriz, casando-se com o rei de Castela, era excluída do trono, pela lei do reino. João das Regras, notavel jurisconsulto, propõe que o Código Justinianeu, com as glosas de Acúrsio e Bártolo, fôsse adotado como lei suplementar D. João encarregou João Mendes, Corregedor da Côrte, de fazer um código das leis pátrias; e, como nada tivesse sido feito até à morte dêsse reí, o seu sucessor, Eduardo, confirmou a incumbência, que, por morte dêsse jurisconsulto, foi transferida para Rui Fernandes, o qual completou no reinado de Afonso $\mathrm{V}$, sendo promulgado na regência do filho D. Pedro, em 1446, sob o nome de Ordenações Afonsinas. Constam elas de cinco livros: da organização judiciária, dos direitos de Majestade, especialmente do processo judicial, dos contratos e das sucessões, dos delitos e das penas. Nesse tempo, diz Melo Freire, reinava, na Lusitânia, o direito romano, com as glosas de Acúrsio e Bártolo, e o direito canônico $\left(^{2}\right)$.

D. Manuel mandou rever essas Ordenações, e, em 1521, publicou as Ordenações Manuelinas, que apresentam um

(1) O povo não podia eleger rei senão na falta de descendente legítimo do último rei, e de parentes agnatos (Inst. Jus. Civ. Lusit., L. III, c. IX, § III.

(2) O. c., págs. 66-67. 
sistema completo de direito pátrio $\left({ }^{2}\right)$. O primeiro livro trata da organização judiciária, e tem 78 títulos. $O$ segundo livro trata dos litigantes, das regalias e dos reguengos; tem 50 títulos. O terceiro, com 90 títulos, trata do processo civil, de maneira completa e brilhante. 0 quarto tem 82 títulos, ocupa-se dos contratos e das sucessões. $O$ quinto, com 113 títulos, compreende o direito criminal e respetivo processo.

\section{O esplendor político da Espanha}

Os reinos cristãos da Espanha foram absorvidos por Aragão e Castela, e êstes se uniram pelo casamento de Isabel de Castela com Fernando, o Católico, de Aragão, em 1467. Durante o reinado deles foi introduzida a Inquisição (1483) e foi extinto o poder mouro na Espanha, pela conquista de Granada (1492), no mesmo ano em que Colombo descobriu a América. Fernando foi sucedido por seu neto, Carlos I, em 1516; e recolhendo êle tambem a sucessão de seu avô, Maximiliano I, imperador da Alemanha, sob o nome de Carlos V, o seu enorme império compreendia, além da Alemanha e da Espanha, os Países Baixos, o condado de França (herdado de seu pai), o ducado de Milão (anexado por êle), o Perú (conquistado por Pizarro, em 1531) e o México (conquistado por Cortês, em 1578). Em 1556, Carlos resignou, e a Espanha, com os Países Baixos e o ducado de Milão, passaram a seu filho legítimo, Felipe II (1556-98), e os territórios alemães a Fernando, irmão de Carlos. Felipe, casado com Maria, rainha da Inglaterra, perdeu a Holanda (1579), uniu Portugal à Espanha, (1580), fez uma desastrada tentativa para

(1) Não se sabe ao certo quais foram os autores dessas Ordenações, mas conjetura-se que nela trabalharam os doutores João Cotrim, João FAria, Pedro Jorge e Cristovão Estevão, então senadores. Em 1514 foi publicada uma edição reconhecida e correta pelo chanceler do reino, dr. RuI BôTo. 
conquistar a Inglaterra, com a "Invincible Armada" (1588), e tentou, sem resultado, impôr a influência espanhola na França.

Na Espanha, nesse período, aparecem as Ordenanças reais de Castela, primeira compilação do reinado de Fernando e Isabel ( ${ }^{1}$ ) (publicada em 1485), as Leis de Fôro, publicadas em 1505, destinadas a sanar contradições entre o Fuero Juzgo, as Partidas e os Ordenamientos), a Nova Recopilação (feita por que as leis do Fuero Juzgo e as dos Ordenamientos não haviam sido copiadas fielmente na coleção de Montalvo) foi concluída em 1562, e teve fôrça de lei em 1567.

\section{o Código Sebastiânico}

Em Portugal, D. Sebastião, o Desejado, põe em vigor o Código Sebastiânico, em 1569, obra de Duarte Nunes de Leão, que nele reuniu, em resumo, as leis extravagantes de D. Manuel, D. João III e D. Sebastião.

\section{As Ordenações Filipinas}

Felipe II, de Castela, e I, de Portugal, mandou elaborar nova coletânea de leis, sendo a tarefa comfiada aos desembargadores Paulo Afonso, Pledro Barbosa, Damião de Aguiar e Jorge de Cabedo, e o trabalho deles, revisto pelos dois últimos e mais os desembargadores Melchior de Amaral, Diogo da Fonseca e Henrique de Sousa, foi publicado e mandado observar, por alvará de 11 de Janeira de 1603; são as Ordenações Filipinas. Essas Ordenações têm o mesmo número de livros, a mesma disposição e a mesma forma de tratar as matérias, que as Ordenações Manuelinas; têm, no entanto, títulos e leis novas, como, no livro I, os títulos 35 a 47 , leis extravagantes do Código

(1) Foi feita por Alonso Dias dE Montalvo. Divide-se em 8 livros. 
Sebastiânico e outras dos mesmos reis a que se refere essa coleção. Essas Ordenações vigoraram em Portugal, até ser promulgado o Código de 1867, e, no Brasil, até à promulgação do Código Civil, que entrou em vigor em 1917.

Entre os comentadores dessas Ordenações merecem citados Manuel Barbosa, Agostinho Barbosa, Manuel Álvares Pegas, Manuel Gonçalves da Silva.

Melo Freire $\left({ }^{1}\right)$ e Coelho da Rocha $\left({ }^{2}\right)$ se manifestaram de maneira depreciativa sôbre essas Ordenações, talvez induzidos por sentimentos patrióticos; mas Cândido Mendes $\left({ }^{3}\right)$ considera essa obra, apesar de seus defeitos, superior às Ordenações Manuelinas, "cujos compiladores não tinham nem podiam dispôr de tantos recursos como os do Código Filipino".

Por essas Ordenações, L. 3, tit. 64, é mantido expressamente o direito romano, como subsidiário.

\section{A lei da Boa Razão}

Em 18 de Agôsto de 1769, é promulgada a Lei da Boa Razão, assim chamada porque dispôs que o Direito Romano sòmente seria subsidiário quando fundado na "boa razão", por essas palavras entendendo-se os princípios essenciais e inalteraveis do direito natural, bem assim os do direito das gentes. Essa lei reformou a Ord., L.I, T.4, $\S 1$, estabelecendo que as glosas do chanceler da Casa da

(1) "Multa praetera habentur in hoc Codice ab Emmanuelino temere inconsiderateque, ac oscitanter desumpta, quae nimurum licet analoga, congruaque essent ceteris in eodem Emmanuelino comprehensis, recentiorum tamen institutis minime conveniebant, non nulla proinde ibidem invenientur omnino otiosa, non nulla inter se contraria, et repugnantia. Compilatores enim nullo delectu, aut discrimine colligentes et jus Emmanuelini Codicis, et novum Extravagantium, quo multa correcta, immutataque fuerant tamque Plautinus ille cocus, jura diversa, et inter se opposita ita commiscent, et confundunt, ut nullo pacto possint sibimet ipsis conciliari”"

(2) Ensaios sobre a história da legislação de Portugal, § 246.

(3) Código Filipino, Introd., p. XXV. 
Suplicação deviam ser observadas sem controvérsia, ampliação ou restrição, sempre que a decisão fosse contrária às Ordenações e mais leis, ou ao direito expresso. Dispôs tambem sôbre a interpretação das leis, quanto ao direito canônico - reservado para os tribunais eclesiásticos, em causas de carater religioso - , bem assim a respeito da aplicação dos estilos e costumes.

\section{O direito na península, a partir de 1805}

Na Espanha, em 1805, é publicada a Nova Recopilação, mandada fazer por Carlos IV, obra de Manuel Lardizabal, concluída por Juan de la Reguera, e que é apenas uma coleção de leis dispersas, cheia de inexatidões e de anacronismos.

Surgem, então, leis avulsas sôbre os expostos (1822), os bens vagos (1835), as substituições fideicomissárias (1841), a condição de estrangeiros (1852), as hipotecas (1861), o registro civil (1870), o casamento civil (1870), a propriedade literária (1879), havendo, porém, matéria codificada (Código de Comércio, de 1829, Código de Processo Civil, de 1856, Código de Organização Judiciária, de 1870, na Espanha; Código Criminal (1852), Código de Processo Civil (1876) e Código Comercial (1888), em Portugal.

Em Portugal aparece o Código Civil, em 1867, e, na Espanha, em 1888.

\section{O Código português}

Depois de outras tentativas, foi o visconde de Seabra incumbido de elaborar o Código Civil, que foi submetido à revisão de uma comissão composta de lentes da Universidade de Coimbra, e de advogados notaveis, e que, promulgado em 1867, entrou em vigor a 22 de Março de 1868, e, nas colônias, a $1 .^{\circ}$ de Julho de 1870.

O Código tem 2538 artigos e divide-se em quatro partes, subdivididas em livros, e estes em capítulos, secções, sub- 
secções e divisões. A parte $1 .^{\mathrm{a}}$, subordinada ao título: "Da capacidade civil", trata das pessôas físicas, das pessôas jurídicas, do domícilio, da ausência, da curadoria e da administração dos bens dos a ela sujeitos, da filiação, da tutelaé a mais extensa, sob o título: "Da aquisição dos direitos" tem tres livros: o n. I trata dos direitos originários e dos que se adquirem por fato e vontade própria, independentemente da cooperação de outrem; e aí vêm os modos originários de adquirir, neles incluindo-se a ocupação dos objetos e produtos naturais comuns (agua, canais, aquedutos), a posse, a prescrição, o direito de trabalho, o trabalho literário e artistico, a propriedade artistica e as dos inventos); o n. II se refere aos direitos que se adquirem por fato e vontade propria e de outro conjuntamente (e aí vêm as obrigações e contratos - inclusive os direitos reais de crédito, os concursos e privilégios creditorios; o n. III trata dos direitos que se adquirem por mero fato de outrem, e dos que se adquirem por simples disposição da lei (e aí coloca a gestão dos negócios e o direito das sucessões). A parte 3. ${ }^{\mathrm{a}}$, como a $1 .^{\mathrm{a}}$, tem um livro único, este sob o título: "Do direito de propriedade", nele incluindo-se os direitos reais sobre a cousa alheia (usufruto, uso, habitação, compascuo, servidões), o direito de fruição (ao qual subordina a accessão), o direito de transformação (ao qual subordina as restrições impostas à propriedade, em defesa da propriedade alheia), o direito de exclusão e de defesa (demarcação, tapagem, direito de defesa), o direíto de restituição e de indenização e o de alienação. A parte $4 .^{\mathrm{a}}$, sob o título "Da ofensa dos direitos e sua reparação", tem dois livros: o n. I, sobre responsabilidade civil, e o $\mathrm{n}$. II, sobre a prova dos direitos e da restituição deles.

Àparte a originalidade da classificação, ha a notar: a) a instituição do Conselho de Família, ao qual compete nomear os tutores e protutores, removê-los, prover sôbre a administração dos bens de menores e os direitos dos mesmos, autorizar-lhes o casamento e as convenções ante- 
nupciais, não sendo tutor dêste o avô, cabendo ao protutor a obrigação de fiscalizar e acompanhar a ação do tutor, e defender os direitos dos menores, quando em oposição aos do tutor; $b$ ) o registro da posse que tenha mais de cinco anos; c) são considerados direitos reais o dote, o arrendamento por mais de dois anos, havendo adiantamento da renda, e por mais de quatro, não havendo; a consignação de rendimentos para pagamento de quantia determinada, ou por determinado número de anos; $d$ ) admite a doação entre esposos, tornando-a livremente revogavel; $e$ ) regula o contrato de serviço doméstico; $f$ ) regula especialmente o contrato de recovagem, de bagagem, de alquilaria, de albergaria ou pousada; $g$ ) admite o juramento como meio de prova, podendo êle ser decisório ou supletório; $h$ ) o casamento é considerado um contrato, mas os católicos o celebrarão pela forma estabelecida na Igreja Católica; mantem os apanágios e os alfinetes.

Leis posteriores organizaram o Registro Predial (1870), o Registro Civil (1878) (estando a matéria agora regulada pelo decreto-lei $n .^{\circ} 22.018$, de 1932 , os privilégios (1868), instituiram o divórcio (decreto de 3 de Novembro de 1910), regularam a proteção dos filhos (decreto n. $^{\circ} 2$, de 25 de Dezembro de 1910), regularam o notariado (O Código do Notariado, que é de 1931, alterou disposições do Código Civil, inclusive na parte referente a testamentos), dispuseram sôbre os acidentes no trabalho (lei n. ${ }^{\circ}$ 1942, de 1936).

\section{o Código espanhol}

O Código espanhol é de 1888. Uma lei desse ano estabelecera que o Código tomaria como base o projeto de 1851, procurando harmonizar os preceitos das leis anteriores, conciliando os ensinamentos da doutrina com as soluções da prática, atendendo às necessidade novas, de acôrdo com o progresso científico e as regras consagradas nas legislações estrangeiras; que o casamento teria duas formas: 
a canônica e a civil; que seria proibida a investigação de paternidade, salvo o caso de delito, declaração expressa do pai, posse de estado, etc.; que na Catalunha e noutras províncias e territórios de direito foral, a nova lei não seria obrigatória, até ulterior deliberação.

O Códiga contém um título preliminar sobre as leis, seus efeitos e regras gerais para sua aplicação, e quatro livros: I) das pessôas; II) dos bens, da propriedade e de suas modificações; III) dos diferentes modos de adquirir a propriedade; IV) das obrigações e contratos.

De acordo com o art. 12, do título preliminar, esse título tem aplicação geral e obrigatória. Quanto ao mais, nas demais provincias e territórios em que subsiste o direito foral, subsistirá este integralmente, sem alteração em seu regime jurídico, escrito e consuetudinário, sendo o Código Civil apenas direito supletório.

Pelo art. $6 .^{\circ}$ da lei de Bases de 11 de Maio de 1888, o Govêrno se obrigou a apresentar às Côrtes, ouvindo a Comissão do Código, os apendices ao mesmo, com as instituições forais que convem conservar em cada uma das províncias e territórios. Não o tendo feito, a ordem da prelação nelas é a seguinte: 1) o aludido título preliminar, e, do livro I, a parte referente ao nascimento e extinção da pessôa física, (menos os artigos referentes à presunção de morte) e das pessôas jurídicas; 2) as leis de carater geral; 3) seus direitos forais; 4) seus direitos supletórios. $O$ direito supletório é: I) para a Catalunha, o direito canônico, o direito romano e o Código Civil; II) para Navarra, o Fuero General, o direito romano e o Código Civil; III) para Biscáia e para as Ilhas Baleares - o Código Civil; IV) para Aragão, o costume, a equidade o Código Civil.

O Código espanhol coloca, no livro I, que tem o título "Das pessôas", o direito de família; no livro II, coloca a posse, o usufruto, o uso, a habitação e as servidões, que considera "modificações" da propriedade; no livro III, trata da ocupação, da doação e da sucessão que são as formas de adquirir o direito de propriedade; no livro IV inclue, 
entre as obrigações e os contratos, o concurso e a prelação dos créditos e a prescrição. Há o casamento canônico e o casamento civil. Os requisitos, a forma e as solenidades para a celebração daquele são "las disposiciones de la Igresia Católica y del Santo Concilío de Trento admitidos como leyes del Reino", e esse casamento produzirá todos os efeitos civis a respeito das pessôas e dos bens dos cônjuges e de seus descendentes. Como o Código português, tem o conselho de família e os protutores. O registro da propriedade é necessário apenas para produzir efeitos em relação a terceiros. $\mathrm{O}$ casamento não é enumerado entre os contratos, como no Código português. Fala em divórcio, mas como em o nosso decreto n. 181 de 1890, não é apenas quoad thorum, ou seja o desquite, como na técnica de nosso Código Civil.

\section{o Código Civil Brasileiro pertence ao sistema do Código português}

Arminjon, Norde e Wolff (Traité de droit comparé) dizem que o Código Civil brasileiro se filia ao sistema francês. Seria estultície pretender diminuir o valor do Código Civil francês; mas o Código brasileiro não se filia ao sistema do mesmo.

O regime de bens, no casamento, não havendo contrato antenupcial, é o do Código português.

$\mathrm{O}$ do Código francês e o da maioria dos códigos estrangeiros é o da comunhão parcial.

Não manteve o nosso Código o instituto dos apanágios, desnecessário quando estabelecida a precedência do cônjuge sôbre os colaterais, nem o de alfinetes, estabelecido para o caso de os cônjuges pertencerem à nobreza. Tambem não temos o Conselho de Família.

O Código português equipara as doações mortis causa (exceto as para casamento) às disposições de última vontade (art. 1.457). É a orientação do Código espanhol 
(art. 620), bem assim a de vários códigos latino-americanos, entre os quais o do Chile (arts. $1.000,1.139$ e 1.141) e o do Uruguai (art. 1.652). O nosso Código se apartou dessa orientação.

O Código português regula as doações entre cônjuges (art. 1.178-1.183), que alguns códigos não admitem (Código argentino, art. 1.807; Cód. uruguaio, art. 1.656. O Cód. italiano, art. 784, igualmente, "salve quelle conformi agli usi"). O Projeto Clovis silenciou a respeito, e os dois artigos da Comissão Revisora, regulando-os, foram suprimidos, em virtude do parecer da Comissão Especial: "Não se proibem as doações entre cônjuges, desde que pela natureza do regime matrimonial forem possiveis".

A sucessão legítima é regulada de forma semelhante no Código português (art. 1.969) e em o nosso (art. 1.603), sendo de notar que em nosso direito o cônjuge vem antes dos colaterais, e que, na linha colateral, no direito português, o direito sucessório vai até o $6 .^{\circ}$ grau (assim foi conservado na lei de 1910), como também em nosso Código Civil, antes da reforma que o limitou ao $4 .^{\circ}$ grau. A limitação ao $60^{\circ}$ é a da maioria das legislações. No direito francês, a ordem de sucessão é completamente diferente, sendo de notar que na linha colateral se estende até ao $120^{\circ}$ grau.

Poderiamos entrar em pormenores, mas desnecessários para o fim que temos em vista, a saber - demonstrar que o direito brasileiro se filia ao direito português, como se vê, por exemplo, em matéria de regime de bens no casamento, e no direito sucessório.

Certamente que em nosso Código Civil, e na legislação posterior, influiram outros direitos, especialmente o Código alemão e o Código francês; a filiaçã̃o, porém, se refere a matérias básicas, e, quanto a elas, é indubitavel a ligação entre o nosso direito e o direito português. 